\title{
Dramatic improvement of acute ischemic stroke management in the Rhone area between 2007 and 2016 : a population based before after prospective study
}

A.M. Schott1,2 , M. Viprey1,2, A. Termoz1,2, J. Haesebaert1,2, M. Chakir1, C. Della Vecchia2, N. Nighoghossian4, S. Cakmak5, S. Meyran6, B. Ducreux7, C. Pidoux7, T. Bony8, M. Douplat8, V. Potinet8, A. Sigal9, L. Derex2,4

1 Hospices Civils of Lyon, Public Health Department, Lyon, France; 2 University of Lyon, University Claude Bernard Lyon 1 - HESPER EA 7425, Lyon, France; 3 Hospices Civils of Lyon, Emergency Department - Hôpital Edouard Herriot, Lyon, France; 4 Hospices Civils of Lyon, Department of Stroke Medicine, Bron, France; 5 Hôpital Nord Ouest, Department of Stroke Medicine, Villefranche-sur-Saône, France; 6 Hôpital St Joseph St Luc, Emergency Department, Lyon, France;

7 Hôpital Nord Ouest, Emergency Department, Villefranche-sur-Saône, France; 8 Hospices Civils of Lyon, Emergency Department - Centre Hospitalier Lyon Sud, Pierre Bénite, France; 9 Hospices Civils of Lyon, Emergency Department- Hôpital Croix Rousse, Lyon, France

Rational : In 2007 a population-based cohort study ("AVC 69") on all consecutive patients with an acute ischemic stroke (IS) admitted to any emergency department (ED) or stroke unit of the Rhône area showed that only $9 \%$ IS patients had eventually access to thrombolysis. In 2016 we conducted a similar study ("STROKE 69") to assess the effectiveness of all actions implemented in the meantime: an increase of Rhône Stroke Units (SU) bed capacities from 6 to 18, and the implementation of a large training program towards emergency physicians and nurses, EMS call center and firemen, and repetitive public campaigns.

\section{AVC 69 STROKE 69

$2007 \quad 2016$ \\ $\mathrm{N}=696 \quad \mathrm{~N}=755$}

\begin{tabular}{|c|c|c|c|}
\hline Women, n (\%) & $362(52)$ & $377(50)$ & 0.43 \\
\hline Age, mean (SD) & $75,1(14)$ & $74,2(15)$ & 0.46 \\
\hline NIHSS, n (\%) & $116(17)$ & $611(81)$ & \multirow{5}{*}{0.0007} \\
\hline$<5$ & $31(27)$ & $275(45)$ & \\
\hline $5-14$ & $60(52)$ & 207 (34) & \\
\hline $15-20$ & $17(14)$ & $75(12)$ & \\
\hline$>20$ & $8(7)$ & $54(9)$ & \\
\hline
\end{tabular}

Call EMS,n (\%) $215(40) \quad 531(70) \quad<0.0001$

$\begin{array}{r}\text { Direct Admission in } \\ \text { Stroke Unit }\end{array} 118(17) \quad 492(88) \quad<0.0001$

Thrombolyse and/or $60(9) \quad 201(27) \quad<0.0001$
Thrombectomy (n\%)

Thrombectomy (n\%) $60(9) \quad 201(27) \quad<0.0001$

\begin{tabular}{|c|c|c|c|}
\hline & $\begin{array}{c}\text { AVC69 } \\
\text { Med (Q1-Q3) } \\
\text { mins }\end{array}$ & $\begin{array}{c}\text { STROKE69 } \\
\text { Med (Q1-Q3) } \\
\text { mins }\end{array}$ & p \\
\hline $\begin{array}{r}\text { Onset to EMS } \\
\text { call }\end{array}$ & $30(5-75)$ & $44(13-168)$ & 0.058 \\
\hline $\begin{array}{l}\text { EMS call to } \\
\text { admission }\end{array}$ & 67 (54-93) & $64(50-78)$ & 0.09 \\
\hline $\begin{array}{r}\text { Onset to } \\
\text { thrombolysis or } \\
\text { thrombectomy }\end{array}$ & $196(174-245)$ & $155(130-195)$ & $<0.0001$ \\
\hline $\begin{array}{r}\text { Imaging to } \\
\text { thrombolysis }\end{array}$ & $70(60-98)$ & $31(20-44)$ & $<0.0001$ \\
\hline $\begin{array}{l}\text { Admission to } \\
\text { thrombolysis }\end{array}$ & $110(55-166)$ & 47 (29-77) & $<0.0001$ \\
\hline
\end{tabular}

Results : After adjustment for potential confounders in multivariate logistic regression models there was still a significant association between the year of the study and the likelihood of having an access to reperfusion therapy. Patients who had an ischemic stroke in 2009 had $40 \%$ less chances to have access to a reperfusion therapy than patients who had an IS in 2016 (adjOR=0.62, $95 \% \mathrm{Cl} 0.39-0.98, \mathrm{p}=0.04$ ), gender was not statistically significantly associated with different access to reperfusion therapy once adjusted for age $(\operatorname{adjOR}=1.06$, $95 \% \mathrm{Cl} 0.71-1.59, \mathrm{p}=0.7)$, one year of aging was associated with a decrease of $1.3 \%$ of likelihood to access a reperfusion therapy $(\operatorname{adjOR}=0.98,95 \% \mathrm{Cl} 0.97-$ $0.99, p=0.046$ ), patients who had not called EMS ("15") was associated with a decreased probability of access to reperfusion therapy (adjOR $=0.57,95 \% \mathrm{Cl} \quad 0.32-0.9$, $\mathrm{p}=0.047$ ), type of transportation did not affect the probability of having access to RPT (adjOR $=0.85,95 \% \mathrm{Cl}$ $0.55-1.30, p=0.4)$, as expected being admitted in an emergency center as first department of admission (vs stroke center) dramatically decreased the likelihood of reperfusion therapy $(\operatorname{adjOR}=0.05,95 \% \mathrm{Cl}$ 0.03-0.07, $\mathrm{p}<0.0001)$.

\section{Conclusion}

Actions undertaken in the Rhone area between 2007 and 2016 increased access to reperfusion from $9 \%$ to $27 \%$ of patients with IS which was mostly due to a significant decrease of in-hospital management times and increase of EMS call ("15") but not to a decrease between symptoms onset and EMS call. 